\title{
Gastric cancer cells alter the immunosuppressive function of neutrophils
}

\author{
SOICHIRO HIRAMATSU, HIROAKI TANAKA, JUNYA NISHIMURA, YOSHIHITO YAMAKOSHI, \\ CHIE SAKIMURA, TATSURO TAMURA, TAKAHIRO TOYOKAWA, KAZUYA MUGURUMA, \\ MASAKAZU YASHIRO, KOSEI HIRAKAWA and MASAICHI OHIRA
}

Department of Surgical Oncology, Osaka City University Graduate School of Medicine, Abeno-ku, Osaka 545-8585, Japan

Received June 1, 2019; Accepted October 24, 2019

DOI: 10.3892/or.2019.7410

\begin{abstract}
Tumor-associated neutrophils (TANs) have an immunosuppressive function and play an important role in tumor progression. However, the detailed mechanism is largely unknown. The present study investigated the immunosuppressive ability of TANs in gastric cancer. Tumor tissue culture supernatant (TTCS) and non-tumor tissue culture supernatant (NTCS) were purified and added to neutrophils. Expression of programmed cell death ligand-1 (PDL-1), 7-amino-actinomycin D and human leukocyte antigen-DR (HLA-DR), and the levels of hydrogen peroxide $\left(\mathrm{H}_{2} \mathrm{O}_{2}\right)$ were determined. Levels of programmed cell death-1 (PD-1) and CD25 were assessed in $\mathrm{T}$ cells co-cultured with neutrophils. Furthermore, $\mathrm{CD}^{+} \mathrm{T}$ cells were co-cultured with dendritic cells and neutrophils to examine their proliferation. CD15 and PD-1 immunohistochemical staining was also performed to explore the positional relationship. The results revealed that the neutrophils incubated with TTCS showed upregulation of PDL-1 expression, as well as a decreases in the ratio of apoptotic cells, expression of HLA-DR, and levels of $\mathrm{H}_{2} \mathrm{O}_{2}$. CD4 $4^{+} \mathrm{T}$ cells co-cultured with neutrophils conditioned with TTCS showed a decrease in proliferation, upregulation of PD-1 expression, and downregulation of CD25 expression. IHC showed that PD-1 ${ }^{+} \mathrm{T}$ cells formed clusters and TANs infiltrated around the clusters. In conclusion, neutrophils in gastric cancer tissue inhibit the proliferation of $\mathrm{CD}^{+} \mathrm{T}$ cells
\end{abstract}

Correspondence to: Dr Hiroaki Tanaka, Department of Surgical Oncology, Osaka City University Graduate School of Medicine, 1-4-3 Asahi-machi, Abeno-ku, Osaka 545-8585, Japan

E-mail: hiroakitan@med.osaka-cu.ac.jp

Abbreviations: GC, gastric cancer; TANs, tumor-associated neutrophils; TTCS, tumor tissue culture supernatant; NTCS, non-tumor tissue culture supernatant; DCs, dendritic cells; PBS, phosphate-buffered saline; PDL-1, programmed cell death ligand-1; PD-1, programmed cell death-1; HLA-DR, human leukocyte antigen-DR; 7-AAD-A, 7-amino-actinomycin D; IHC, immunohistochemistry

Key words: tumor-associated neutrophils, gastric cancer, immunology, immunosuppression, tumor microenvironment and may form a local immunosuppressive environment through the PD-1/PDL-1 pathway.

\section{Introduction}

Gastric cancer (GC) is one of the leading causes of death due to cancer. Yet, treatment outcomes have improved with the development and improvement in multidisciplinary therapy $(1,2)$. The occurrence, development and prognosis of GC are closely related to the crosstalk among different immune cells in the tumor microenvironment (3-7). The relationship between GC progression and immune cells has recently been receiving increased attention (8).

Neutrophils are the most abundant type of white blood cell, and are an essential component of the innate immune system (9). They characteristically arrive rapidly at sites of infection, injury, and tumors and release a variety of cytokines and toxic molecules to eliminate pathogens and elicit an acute inflammatory response (8-10). In particular, intratumoral neutrophils (tumor-associated neutrophils: TANs) are involved in angiogenesis and lymphangiogenesis, which lead to tumor progression $(4,6-8,11,12)$. We previously reported that TANs in GC tissue are correlated with lymph node metastasis and systemic inflammatory markers such as the neutrophil-lymphocyte ratio, platelet-lymphocyte ratio, and lymphocyte-monocyte ratio. Various immune cells including $\mathrm{T}$ cells, natural killer cells, M2 macrophages, dendritic cells (DCs), and neutrophils often infiltrate cancer tissues.

Although tumor-specific CD4 ${ }^{+} \mathrm{T}$ lymphocytes play an indispensably important role in the antitumor immune response at the tumor site, regulatory T cells and myeloid suppressor cells are the major components of the immune suppressive cellular network. Some types of TANs have similar immunosuppressive functions as those of G-myeloid suppressor cells (6,13-19); however, the underlying mechanism is still unclear. The present study aimed to investigate the immunosuppressive ability of neutrophils in GC tissue and to explore the influence of neutrophils on the proliferation of $\mathrm{CD}^{+} \mathrm{T}$ cells.

\section{Materials and methods}

Neutrophil isolation and culture. Human neutrophils were isolated from peripheral blood of healthy volunteers using 
Polymorphprep (Axis-Shield) and centrifuged (400 x g and $20 \mathrm{~min}$ ), resulting in a purity of $\geq 85 \%$. Cells were washed three times in complete RPMI-1640 medium (Sigma-Aldrich; Merck KGaA) with $100 \mathrm{U} / \mathrm{ml}$ penicillin, $100 \mu \mathrm{g} / \mathrm{ml}$ streptomycin, L-glutamine (HyClone; GE Healthcare), and 10\% fetal bovine serum (Gibco; Thermo Fisher Scientific, Inc.). Neutrophils were then incubated in complete RPMI-1640 medium (Sigma-Aldrich; Merck $\mathrm{KGaA}$ ) at $37^{\circ} \mathrm{C}$ in $5 \% \mathrm{CO}_{2}$ for $16 \mathrm{~h}$.

$\mathrm{CD}^{+} \mathrm{T}$ cell isolation and culture. Peripheral blood mononuclear cells were also isolated by density centrifugation (400 x g and $20 \mathrm{~min}$ ) using Polymorphprep, washed three times in complete RPMI-1640 medium, and separated into CD4-positive and -negative cells using a CD4 Isolation Kit (Miltenyi Biotec) according to the manufacturer's instructions, resulting in a purity of $\geq 90 \%$. Following this, $\mathrm{CD}^{+} \mathrm{T}$ cells were incubated in complete RPMI- 1640 at $37^{\circ} \mathrm{C}$ in $5 \% \mathrm{CO}_{2}$ for $24 \mathrm{~h}$.

Preparation of tumor tissue culture supernatants (TTCSs), non-tumor tissue culture supernatants (NTCSs) and supernatant-conditioned neutrophils. A single-cell suspension was prepared from surgical specimens from patients who underwent gastrectomy at the Osaka City University (Osaka, Japan). Supernatants purified from tumor tissue or the human scirrhous GC cell line, OCUM-12 (20), were defined as TTCSs, whereas the supernatants purified from non-tumor tissues at least $5 \mathrm{~cm}$ distant from the tumor site were defined as NTCSs. Both TTCSs and NTCSs were purified after culturing $1 \times 10^{6}$ cells $/ \mathrm{ml}$ in complete RPMI- 1640 at $37^{\circ} \mathrm{C}$ in $5 \% \mathrm{CO}_{2}$ for $24 \mathrm{~h}$. To generate supernatant-conditioned neutrophils, neutrophils from healthy volunteers were cultured with 50\% TTCS or NTCS for $16 \mathrm{~h}$, and then washed with complete RPMI-1640 three times. Neutrophils cultured in RPMI-1640 medium were used as controls.

Neutrophil stimulation with TTCS or NTCS. Neutrophils from healthy volunteers were stimulated with $50 \%$ TTCS or $50 \%$ NTCS for $16 \mathrm{~h}$. After stimulation, the percentage of 7-amino-actinomycin D-positive cells and the expression of programmed cell death ligand-1 (PDL-1) and human leukocyte antigen-DR (HLA-DR) were measured. In addition, the expression of PDL-1 in neutrophils infiltrating the GC tissue was compared with expression in neutrophils infiltrating normal mucosa (at least $5 \mathrm{~cm}$ distant from the tumor site) with flow cytometry (LSRII; BD Biosciences). $\mathrm{H}_{2} \mathrm{O}_{2}$ levels were measured using a Hydrogen Peroxide Colorimetric Detection Kit (Enzo Life Science).

In vitro neutrophil-CD4 ${ }^{+} \mathrm{T}$ cell co-culture system. $\mathrm{CD} 4^{+}$ T cells $\left(1 \times 10^{5}\right)$ were seeded in $500 \mu \mathrm{l}(20)$ complete RPMI-1640 in 24-well plates. Neutrophils incubated with 50\% TTCS or $50 \%$ NTCS, adjusted to $1 \times 10^{5}$ cells per $500 \mu 1$ complete RPMI-1640 medium, were co-cultured with $\mathrm{CD}^{+}{ }^{+} \mathrm{T}$ cells using Cell Culture Inserts (BD Falcon; BD Biosciences) at $37^{\circ} \mathrm{C}$ in $5 \% \mathrm{CO}_{2}$ for $16 \mathrm{~h}$. Expression of programmed cell death-1 (PD-1) and CD25 in CD4 ${ }^{+} \mathrm{T}$ cells was measured with flow cytometry.

Allogeneic mixed lymphocyte reaction. Immature DCs were prepared by culturing adherent peripheral blood monocytes for 7 days in RPMI-1640 medium supplemented with $10 \%$ fetal bovine serum (FBS), recombinant human granulocyte macrophage colony-stimulating factor ( $\mathrm{rH}$ GM-CSF) $(50 \mathrm{ng} / \mathrm{ml})$, and interleukin-4 (IL-4) $(50 \mathrm{ng} / \mathrm{ml})$. To induce maturation of DCs, lipopolysaccharide $(100 \mathrm{ng} / \mathrm{ml})$ was added to the cell culture for $24 \mathrm{~h}$ before harvesting. Allogenic DCs and neutrophils incubated with TTCS or NTCS were added to $\mathrm{CD} 4^{+} \mathrm{T}$ cells labelled with carboxyfluorescein diacetate succinimidyl ester (CFDA-SE) (Tonbo Biosciences) at a ratio of 1:10:10, and co-cultured for 4 days in complete RPMI-1640 medium at $37^{\circ} \mathrm{C}$ in $5 \% \mathrm{CO}_{2}$, followed by the analysis of CFDA-SE signal with flow cytometry on gated CD4 lymphocytes to explore the proliferative capacity of the $\mathrm{CD} 4^{+} \mathrm{T}$ cells.

Patients and surgical specimens. We retrospectively examined surgical specimens from patients who underwent gastrectomy for GC with pathological stage II or III at the Department of Surgical Oncology (Osaka City University, Japan) from January 2007 to March 2013. The average age is 64.11 years and the ratio of male to female is 84 to 31 . The specimens were formalin-fixed and paraffin-embedded tissues obtained from 115 primary tumors, which were analyzed using immunohistochemistry (IHC). Pathological staging was performed according to the 7th edition of the International Union Against Cancer Tumour-Node-Metastasis (TNM) classification (https://www. wiley.com/en-us/TNM+Classification+of+Malignant+Tumours $\% 2 \mathrm{C}+7$ th+Edition-p-9781444358964). Postoperative follow-ups were performed every 3 months for the first 2 years, and then every 6 months during years $3-5$. The retrospective protocol of the present study was approved by the Osaka City University Ethics Committee, and all patients provided informed consent for collection and analysis of the specimens.

IHC. To assess the locational relationship between TANs and PD- $1^{+} \mathrm{T}$ cells, IHC was performed. Sections with a thickness of $4 \mu \mathrm{m}$ were obtained from the paraffin-embedded blocks. After incubation at $60^{\circ} \mathrm{C}$ for $10 \mathrm{~min}$, the sections were deparaffinized using xylene and rehydrated using a graded series of ethanol. The slides were subsequently washed twice for $5 \mathrm{~min}$ in phosphate-buffered saline (PBS). Endogenous peroxidase activity was blocked for $15 \mathrm{~min}$ in absolute methanol containing 3\% hydrogen peroxide. After washing the sections in PBS, the samples were microwaved for $10 \mathrm{~min}$ for antigen retrieval. Non-specific binding was blocked using a non-specific staining blocking reagent (Dako; Agilent Technologies, Inc.). The sections were then incubated overnight at $4^{\circ} \mathrm{C}$ with mouse monoclonal antibodies [CD15 (cat. no. ab17080) or PD-1 (cat. no. ab137132), dilution 1:100; Abcam], and subsequently washed with PBS for 10 min before incubating with appropriate secondary antibodies [goat anti-human IgG H\&L (HRP); cat. no. ab6858; dilution 1:100] or $10 \mathrm{~min}$ at room temperature. After washing the sections with PBS, the samples were visualized using 3-3'-diaminobenzidine for $5 \mathrm{~min}$ and then counter-stained using hematoxylin before mounting. We obtained an average value from five hot spot high-power fields, and median values of both CD15 and PD-1 were calculated for the 115 patients. Patients were divided into high and low $\mathrm{CD} 15^{+}$ TAN or PD $-1^{+} \mathrm{T}$ cell groups, based on each median number. The correlation between CD15+ TANs and PD- $1^{+} \mathrm{T}$ cells was examined using the Chi-square test and a scatter plot. 
A
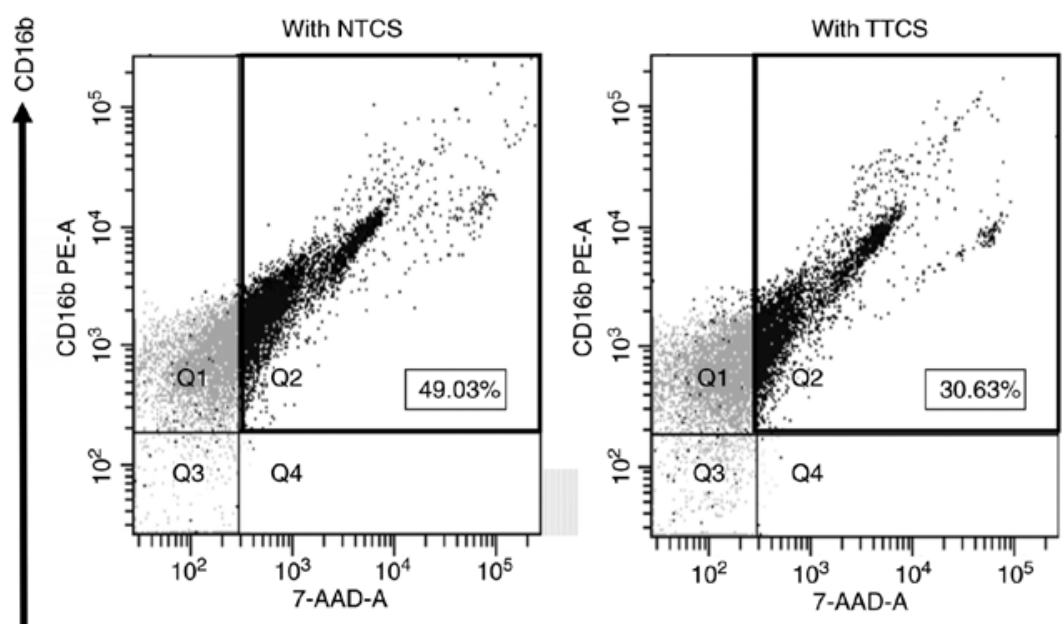

TAAD

\section{B}

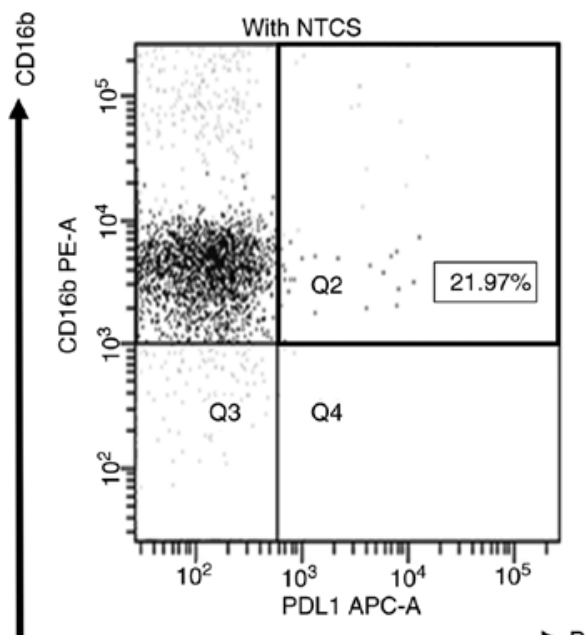

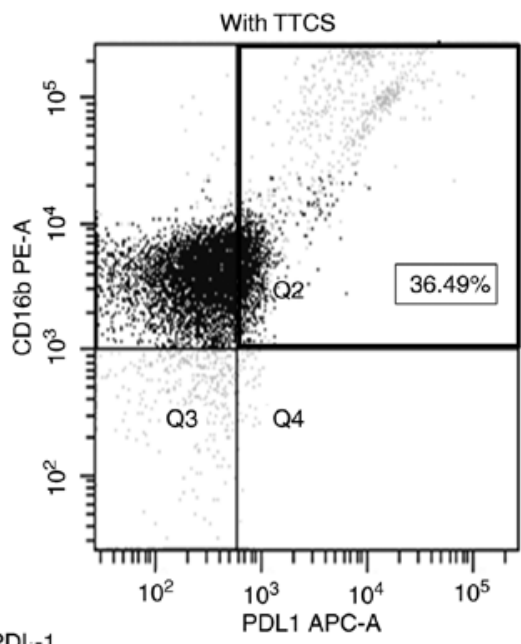

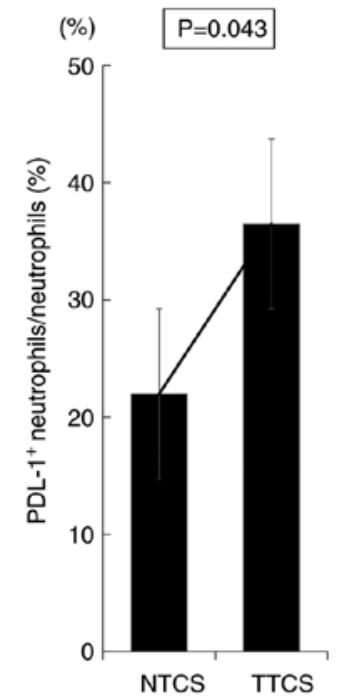

Figure 1. Characteristic changes in neutrophils in GC tissue. (A) Comparison of the apoptotic ratio of neutrophils incubated with TTCS or NTCS. Neutrophils incubated with TTCS showed a significantly decreased ratio of apoptotic cells compared to neutrophils incubated with NTCS. In (A) Q1, CD16b-positive/7-AAD-A-negative;Q2,CD16b-positive/7-AAD-A-positive; Q3,CD16b-negative/7-AAD-A-negative; Q4,CD16b-negative/7-AAD-A-positive. (B) Induction of PDL-1 expression in neutrophils by GC tissue. Neutrophils incubated with TTCS showed clearly upregulated expression of PDL-1 compared to neutrophils incubated with NTCS. GC, gastric cancer; TTCS, tumor tissue culture supernatant; NTCS, non-tumor tissue culture supernatant; PDL-1, programmed cell death ligand-1; HLA-DR, human leukocyte antigen-DR; 7-AAD-A, 7-amino-actinomycin D.

Ethical approval and informed consent. This study's retrospective protocol was approved by the Osaka City University Ethics Committee (Osaka, Japan), and informed consent was obtained in writing from all patients. All volunteers provided oral and written informed consent and agreed to the use of their samples in scientific research and all participants for collection and analysis of the specimens in this study.

Statistical analysis. Data are expressed as mean value \pm standard deviation (SD). Continuous variables were compared using the Student's t-test, and categorical variables were compared using the Chi-square test. Correlations between parameters were assessed using the Pearson correlation analysis and linear regression analysis as appropriate. Differences were considered statistically significant at P-values of $<0.05$. All statistical analyses were performed using JMP software (version 11; SAS Institute).

\section{Results}

Characteristic changes in neutrophils in GC tissue. To evaluate the impact of GC tissue on neutrophils, we analyzed the percentage of apoptotic cells and the expression of PDL-1 in neutrophils conditioned with TTCS or NTCS.TTCS-conditioned neutrophils showed a significantly lower percentage of apoptotic cells (Fig. 1A) and higher expression of PDL-1 (Fig. 1B) compared to NTCS-conditioned neutrophils. Neutrophils directly isolated from GC tissue showed significantly higher expression of PDL-1 than those from normal mucosa (Fig. 1C). Mature human neutrophils have antigen-presenting ability similar to DCs (21-23). Thus, we examined the antigen-presenting ability of neutrophils conditioned with TTCS or NTCS. Neutrophils treated with TTCS showed significantly reduced expression of HLA-DR compared to those incubated with NTCS (Fig. 1D). 

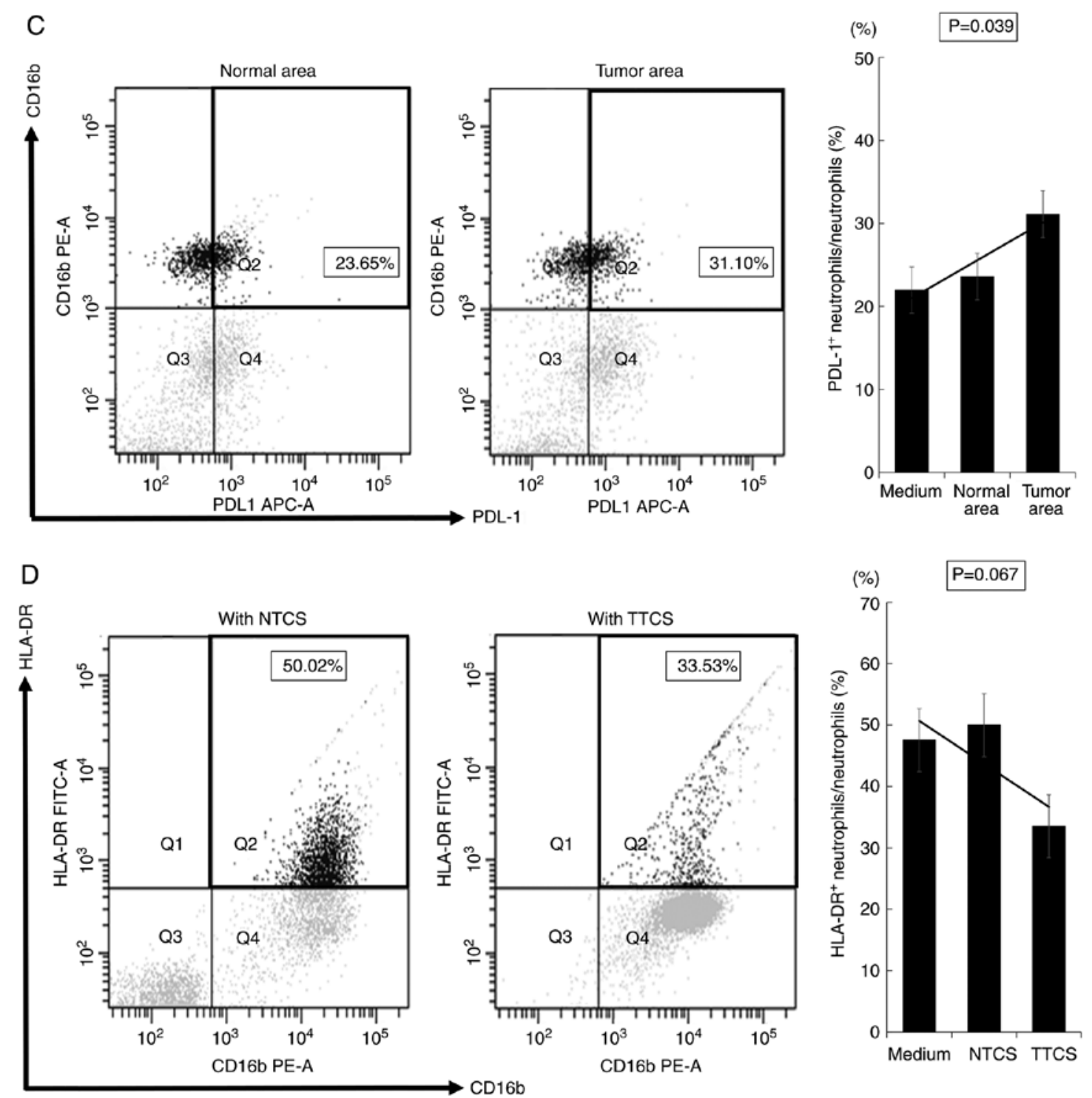

Figure 1. Continued. (C) Comparison of the ratio of PDL-1 $1^{+}$neutrophils in the tumor area and normal area. Neutrophils infiltrating the tumor area showed significantly increased expression of PDL-1. In (B and C) Q1, CD16b-positive/PDL-1-negative; Q2, CD16b-positive/PDL-1-positive; Q3, CD16b-negative/PDL-1-negative; Q4, CD16b-negative/PDL-1-positive. (D) Reduction of HLA-DR in neutrophils by TTCS. Neutrophils incubated with TTCS tended to show decreased expression of HLA-DR compared to neutrophils incubated with NTCS. In (D) Q1, HLA-DR-positive/CD16b-negative; Q2, HLA-DR-positive/CD16b-positive; Q3, HLA-DR-negative/CD16b-negative; Q4, HLA-DR-negative/CD16b-positive. GC, gastric cancer; TTCS, tumor tissue culture supernatant; NTCS, non-tumor tissue culture supernatant; PDL-1, programmed cell death ligand-1; HLA-DR, human leukocyte antigen-DR; 7-AAD-A, 7-amino-actinomycin D.

Impact of neutrophils treated with TTCS on $C D 4^{+} T$ cells. To explore the impact of TANs on $\mathrm{CD}^{+} \mathrm{T}$ cells, we co-cultured $\mathrm{CD}^{+} \mathrm{T}$ cells and neutrophils. $\mathrm{T}$ cells co-cultured with TTCS-conditioned neutrophils showed significantly higher expression of PD-1 than T cells co-cultured with NTCS-conditioned neutrophils (Fig. 2A and B). Next, we focused on $\mathrm{CD} 25$, which is an activating factor of $\mathrm{T}$ cells. $\mathrm{CD} 4^{+} \mathrm{T}$ cells co-cultured with neutrophils conditioned with TTCS showed lower expression of CD25 (Fig. 2C). Next, we examined whether neutrophils possess immunosuppressive ability. To examine the impact of neutrophils on $\mathrm{CD}^{+} \mathrm{T}$ cell proliferation, a co-culture assay was performed using $\mathrm{CD}^{+}$ $\mathrm{T}$ cells, DCs and neutrophils. $\mathrm{CD} 4^{+} \mathrm{T}$ cells isolated from a healthy volunteers proliferated when co-cultured with allogeneic DCs. After further co-culturing of these T cells with autologous neutrophils conditioned with NTCS or TTCS for
4 days, the change in their proliferative ability was examined. Proliferation of $\mathrm{CD} 4^{+} \mathrm{T}$ cells co-cultured with neutrophils conditioned with TTCS was suppressed. On the other hand, the proliferative ability of $\mathrm{CD}^{+} \mathrm{T}$ cells co-cultured with neutrophils conditioned with NTCS was not affected (Fig. 3).

Furthermore, to investigate the ability of neutrophils to kill cancer cells in the tumor microenvironment, we measured the levels of reactive oxygen species such as $\mathrm{H}_{2} \mathrm{O}_{2}$. TTCS-conditioned neutrophils had significantly reduced levels of $\mathrm{H}_{2} \mathrm{O}_{2}$ compared to NTCS-conditioned neutrophils (Fig. 4).

Distribution of PD- $1^{+}$cells and TANs in GC tissue. IHC showed that PD- $1^{+} \mathrm{T}$ cells formed clusters both in primary tumors and lymph nodes (Fig. 5A-D), and CD15+ TANs infiltrated around the clusters (Fig. 5E-H). Our analysis indicated a positive 
A

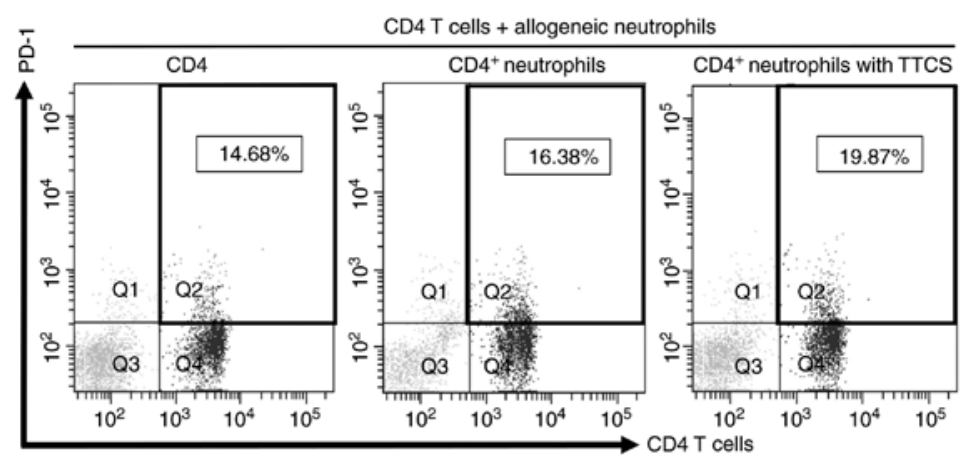

B

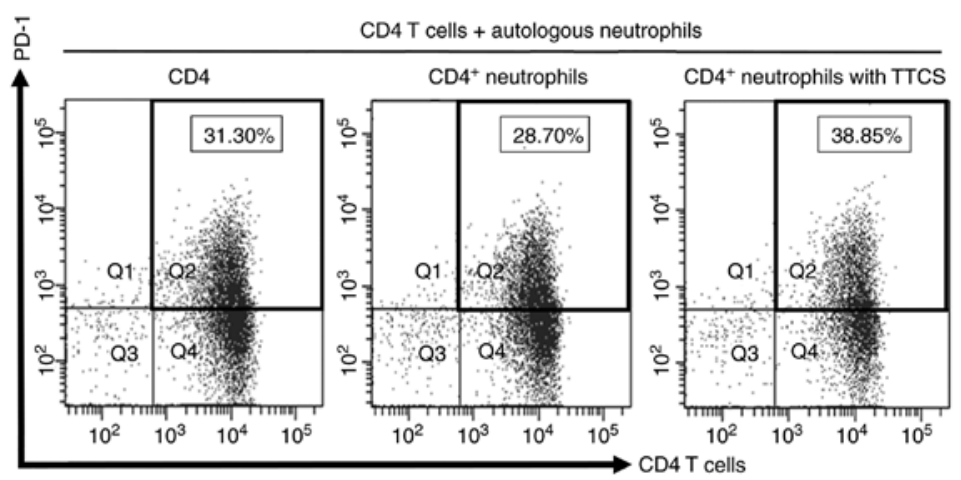

C

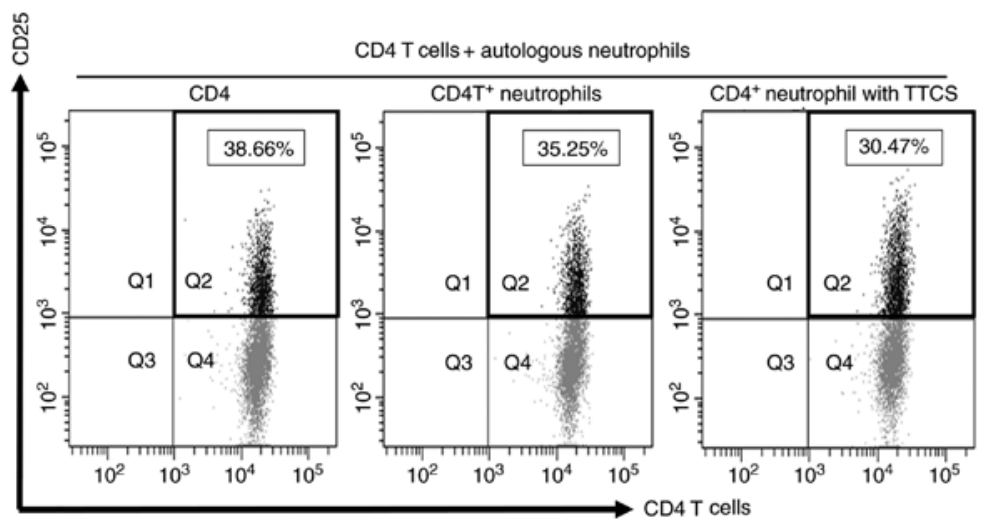

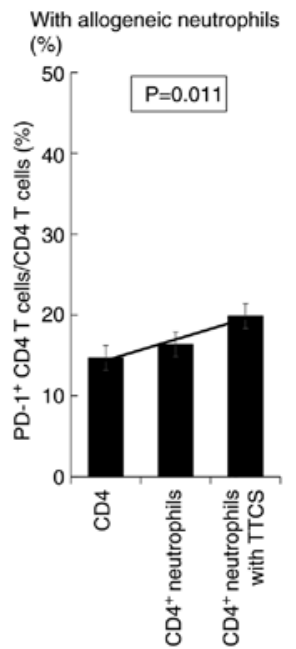

With autologous neutr

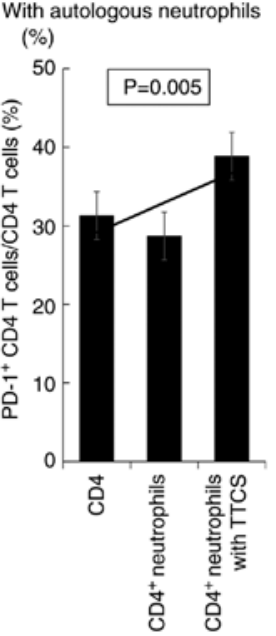

With autologous neutrophils

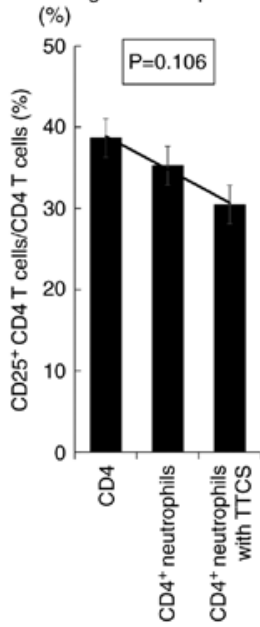

Figure 2. Impact of neutrophils on $\mathrm{CD} 4^{+} \mathrm{T}$ cells. (A) $\mathrm{CD} 4^{+} \mathrm{T}$ cells co-cultured with allogenic neutrophils and (B) co-cultured with autologous neutrophils. $\mathrm{CD}^{+} \mathrm{T}$ cells co-cultured with allogenic or autologous neutrophils incubated with TTCS showed significantly upregulated expression of PD-1. In (A and B) Q1, PD-1-positive/CD4-negative; Q2, PD-1-positive/CD4-positive; Q3, PD-1-negative/CD4-negative; Q4, PD-1-negative/CD4-positive. (C) Expression of $\mathrm{CD} 25$ in $\mathrm{CD}^{+} \mathrm{T}$ cells co-cultured with autologous neutrophils. CD4 ${ }^{+} \mathrm{T}$ cells co-cultured with autologous neutrophils incubated with TTCS tended to show downregulation of CD25 expression. In (C) Q1, CD2-positive/CD4-negative; Q2, CD25-positive/CD4-positive; Q3, CD25-negative/CD4-negative; Q4, CD25-negative/CD4-positive. TTCS, tumor tissue culture supernatant; PD-1, programmed cell death-1.

correlation between the expression of PD-1+ $\mathrm{T}$ cells and the number of infiltrating CD15 $5^{+}$TANs in GC tissue (Table I). A scatter plot additionally showed a weak positive correlation between $\mathrm{CD} 15^{+}$TANs and PD-1+ $\mathrm{T}$ cells (Fig. 6).

\section{Discussion}

We previously reported that neutrophils in GC tissue (TANs) are associated with poor prognosis. In that report, we showed 


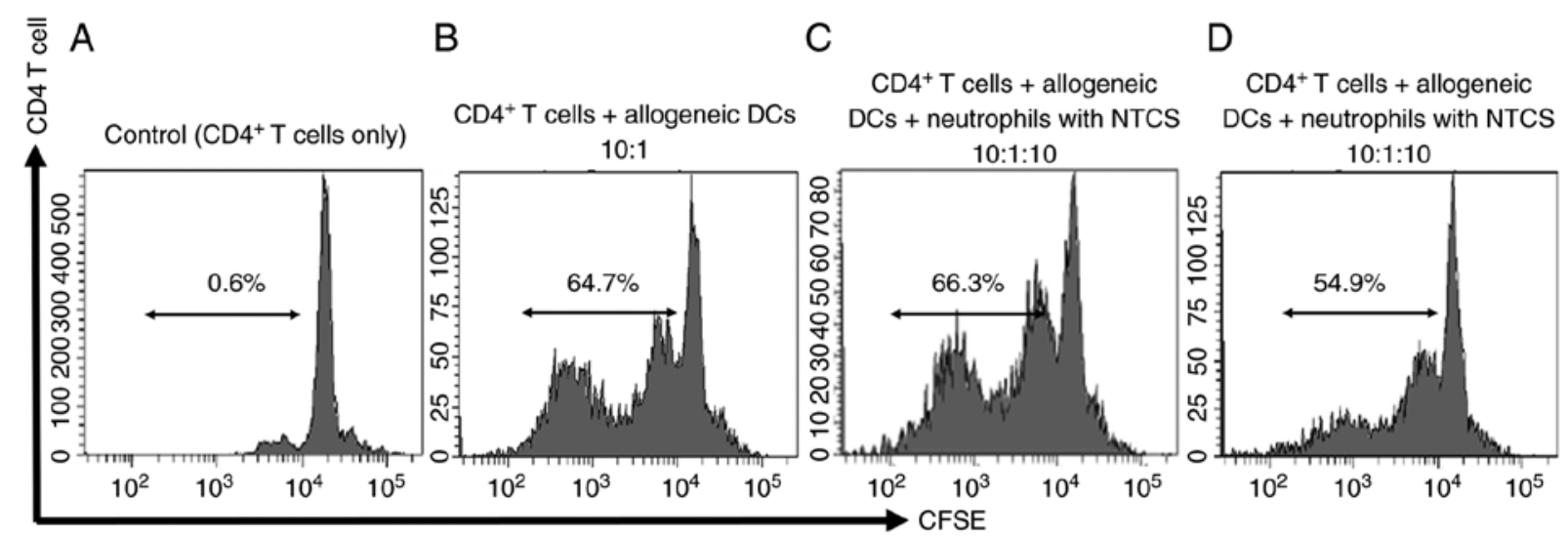

Figure 3. Suppression of the proliferation of $\mathrm{CD}^{+} \mathrm{T}$ cells by neutrophils. (A) $\mathrm{CD} 4^{+} \mathrm{T}$ cells (control). (B) Co-cultured with allogenic DCs. (C) Co-cultures of allogenic DCs and neutrophils incubated with NTCS. (D) Co-cultures of allogenic DCs and neutrophils incubated with TTCS. CD4 ${ }^{+} \mathrm{T}$ cells co-cultured with neutrophils incubated with TTCS showed suppressed proliferative ability. In contrast, the proliferation ability of CD4 ${ }^{+} \mathrm{T}$ cells co-cultured with neutrophils incubated with NTCS was not suppressed. DCs, dendritic cells; TTCS, tumor tissue culture supernatant; NTCS, non-tumor tissue culture supernatant.

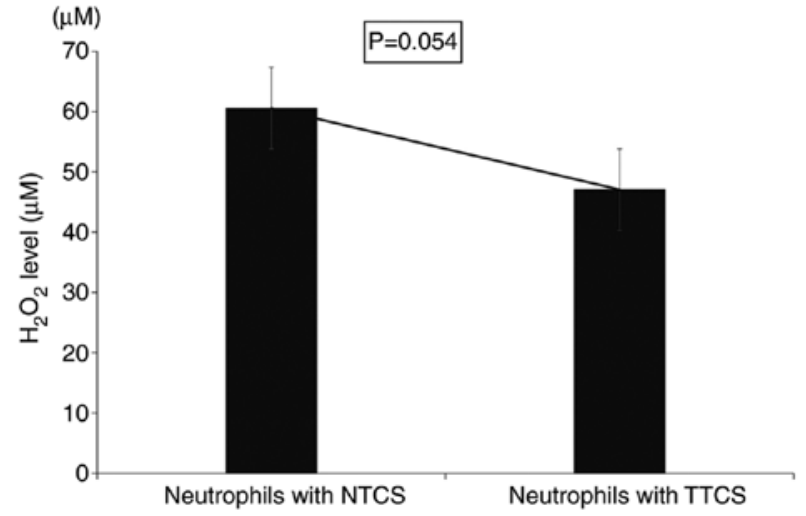

Figure 4. Secretion of $\mathrm{H}_{2} \mathrm{O}_{2}$ by neutrophils. The levels of $\mathrm{H}_{2} \mathrm{O}_{2}$ secreted from neutrophils incubated with TTCS tended to be lower than neutrophils incubated with NTCS. TTCS, tumor tissue culture supernatant; NTCS, non-tumor tissue culture supernatant.

the relationship between infiltration of TANs and the systemic neutrophil-lymphocyte ratio, which could be reflective of the immune response $(6,7)$. The present study revealed that neutrophils conditioned with TTCS displayed altered characteristics such as prolonged lifespan, upregulation of programmed cell death ligand-1 (PDL-1) expression, downregulation of human leukocyte antigen-DR (HLA-DR) expression and production of $\mathrm{H}_{2} \mathrm{O}_{2}$. PDL-1 expression on neutrophils is elevated in various cancer types such as GC, HIV-associated cancers, breast cancer and lung cancer (8-12).

Extension of the neutrophil lifespan by cancer cells has also been pointed out in previous studies (24-28), and the same result was obtained in our experiments. These results suggest that neutrophils in the local tumor microenvironment are part of the immunosuppressive mechanism mediated by the PD-1/PDL-1 pathway $(25,28,31)$ and function over a long period of time to allow tumor growth. We previously reported that patients in the high $\mathrm{CD} 15^{+} \mathrm{TAN}$ group demonstrated a worse prognosis than those in the low $\mathrm{CD}^{+} 5^{+} \mathrm{TAN}$ group, and that high $\mathrm{CD} 15^{+} \mathrm{TAN}$ infiltration in tumor-draining lymph nodes is an independent prognostic factor for patients with GC $(6,7)$. Such an immunosuppressive
Table I. Correlation between the expression of PD- $1^{+} \mathrm{T}$ cells and the number of infiltrating $\mathrm{CD} 15^{+}$TANs in gastric cancer tissue.

\begin{tabular}{|c|c|c|c|c|}
\hline \multirow[b]{2}{*}{$\mathrm{CD} 5^{+} \mathrm{TANs}$} & \multirow[b]{2}{*}{$\mathrm{N}$} & \multicolumn{2}{|c|}{ PD- $1^{+} \mathrm{T}$ cells } & \multirow[b]{2}{*}{ P-value } \\
\hline & & High & Low & \\
\hline High & 58 & 36 & 22 & $0.006^{\mathrm{a}}$ \\
\hline Low & 57 & 21 & 36 & \\
\hline
\end{tabular}

${ }^{\mathrm{a}} \mathrm{P}<0.05$, significant difference. PDL-1, programmed cell death ligand-1; TANs, tumor-associated neutrophils.

function of TANs may contribute to the poor prognosis of patients with GC.

Furthermore, neutrophils have antigen-presenting ability similar to DCs $(23,24)$, and reduced expression of HLA-DR suggests a reduction in this ability. To the best of our knowledge, this is the first demonstration of a reduction in HLA-DR on neutrophils. Additionally, we showed that neutrophils conditioned with TTCS induced PD-1 expression in CD4 ${ }^{+}$ $\mathrm{T}$ cells and decreased the proliferation of $\mathrm{CD}^{+} \mathrm{T}$ cells, indicating that neutrophils that have gained an immunosuppressive function are present in GC tissue $(24,25)$. Several reports have shown that immune cells sensitized to tumors suppress $\mathrm{T}$ cell proliferation. Our research on neutrophils showed similar results $(25,26,31,32)$. Moreover, the positional relationship between $\mathrm{CD} 15^{+}$TANs and $\mathrm{PD}^{+} \mathrm{T}$ cells as observed with IHC revealed that clusters of $\mathrm{PD}^{+}{ }^{+} \mathrm{T}$ cells are at the center of the immune response mediated by TANs. Tumor-infiltrating lymphocytes including $\mathrm{T}$ cells and $\mathrm{B}$ cells are mostly organized as clusters, and various immune reactions are thought to occur in GC tissue (26). Our IHC showed that the PD- $1^{+}$lymphocyte population exists in clusters, and their activity may be affected by crosstalk with TANs. TANs may induce the PD-1/PDL-1 pathway and suppress the proliferation of $\mathrm{CD} 4^{+} \mathrm{T}$ cells. PDL-1 expression is associated with aggressive subtypes of several types of cancer and poor prognosis $(3,27-29)$. Blockade of the PD-1/PDL-1 pathway has 
A

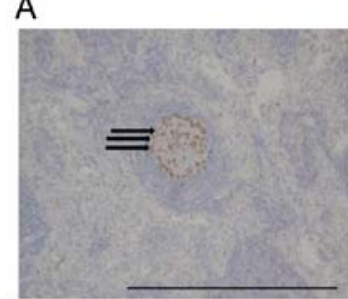

E

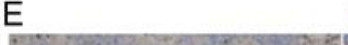

B

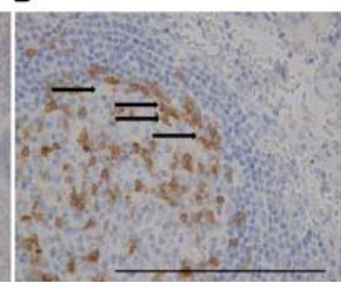

$\mathrm{F}$
C

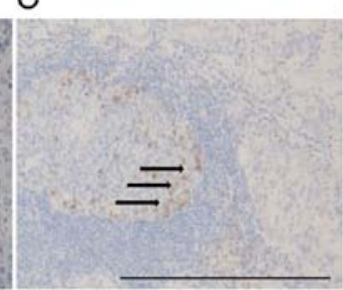

G
D

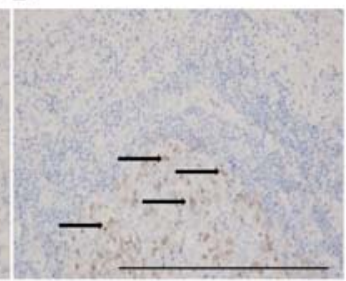

$\mathrm{H}$

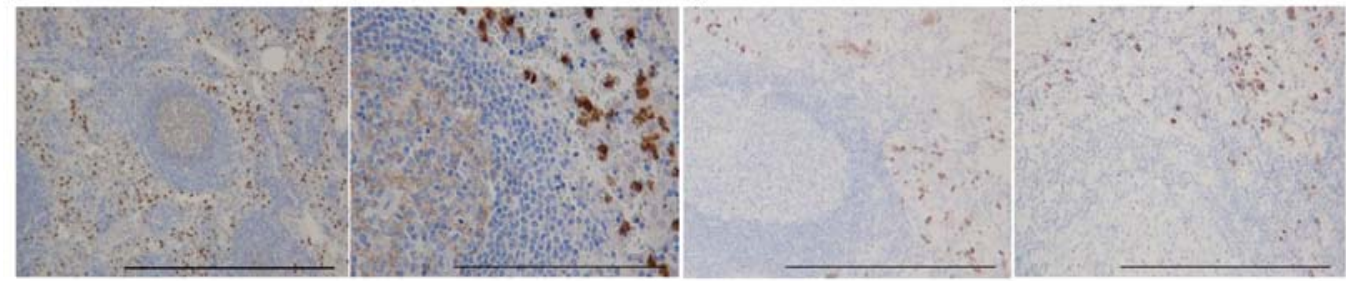

Figure 5. Immunohistochemical staining for CD15 and PD-1 in primary tumors and lymph nodes. (A) High expression of PD-1 in lymph nodes. Magnification x40; scale bar, $1 \mathrm{~mm}$. (B) High expression of PD-1 in lymph nodes. Magnification x400; scale bar, $0.1 \mathrm{~mm}$. (C and D) High expression of PD-1 in a primary tumor. Magnification x100; scale bar, $0.25 \mathrm{~mm}$. PD- $1^{+} \mathrm{T}$ cells formed clusters both in primary tumors and lymph nodes. (E) The same section as that in A was stained for CD15 in lymph nodes. Magnification x40; scale bar, $1 \mathrm{~mm}$. (F) The same section as that in B was stained for CD15 in lymph nodes. Magnification x400; scale bar, $0.1 \mathrm{~mm}$. (F and G) The same sections as those in C and D were stained for CD15 in primary tumors. Magnification x100; scale bar, $0.25 \mathrm{~mm}$. $\mathrm{CD} 5^{+}$TANs tended to infiltrate and surround the cluster formed by PD-1 ${ }^{+}$T cells. TANs, tumor-associated neutrophils; PD-1, programmed cell death-1.

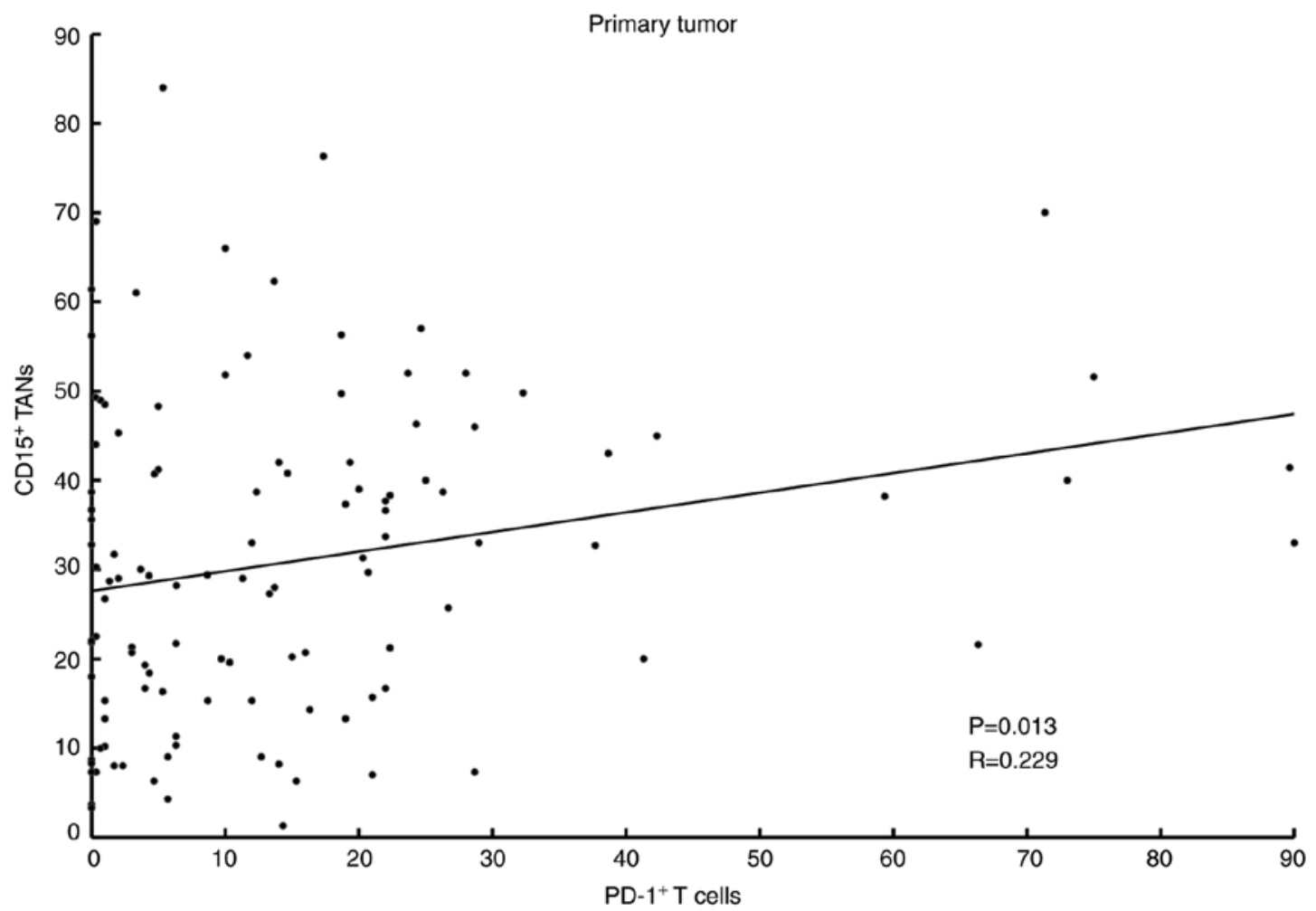

Figure 6. Correlation between TANs and PD-1+ $\mathrm{T}$ cells in GC. Scatter plot shows a weak positive correlation between CD15 $5^{+} \mathrm{TANs}$ and PD-1 $1^{+} \mathrm{T}$ cells. GC, gastric cancer; TANs, tumor-associated neutrophils; PD-1, programmed cell death-1.

also attracted attention in $\mathrm{GC}$ as a new promising therapeutic approach in oncology $(5,8,32,33)$.

Many immune cells such as tumor-associated macrophages, cancer-associated fibroblasts and regulatory $\mathrm{T}$ cells migrate into the tumor to form an immunosuppressive environment (5,30-32). Of the immune cells reported, the immunosuppressive capacity of neutrophils through PDL-1 expression has not been well studied. Thus, investigation of
PDL-1 expression induced by TANs in cancer cells has important implications. Which tumor-infiltrating immune cells initiate the immunosuppressive microenvironment remains unclear. Neutrophils may be the first to infiltrate a tumor since neutrophils are the first immune cells that respond to infection and are involved in removal of foreign bodies (9). Therefore, our findings suggest that PDL-1+ ${ }^{+}$TANs may be a new target for the treatment of GC in the future. 
The present study has several limitations. First, in this experimental model, the detailed mechanism of how TAN infiltration of GC tissue results in immunosuppression and suppression of $\mathrm{CD}^{+} \mathrm{T}$ cell function is lacking. Because our study did not provide direct evidence for neutrophils as the first immune cells to form an immunosuppressive environment in GC tissue, further in vitro experiments are required to evaluate immune regulation by TANs. Second, TANs have two phenotypes: Anti-tumorigenic (N1) or pro-tumorigenic (N2) (34-37), and our study did not address which type of TAN contributed to the results obtained in this study. Hence, further investigation regarding the phenotypes of TANs in relation to our study results is warranted.

In conclusion, our study demonstrated that GC cells possess the potential to alter the characteristics of neutrophils and induce upregulation of immune check point molecules to inhibit $T$ cell proliferation. Therefore, our findings suggest that regulation of tumor-infiltrating neutrophils is critical to overcome the immunosuppressive microenvironment of GC.

\section{Acknowledgements}

Not applicable.

\section{Funding}

HT was supported by Grants-in-Aid for Scientific Research from the Ministry of Education, Culture, Sports, Science and Technology (grant no. 26461990) for this study.

\section{Availability of data and materials}

All data generated or analyzed during this study are included in this published article.

\section{Authors' contributions}

$\mathrm{SH}, \mathrm{JN}, \mathrm{YY}$ and CS performed experiments described in the study. TT and KM contributed to the collection of samples, analysis, and data management. MY provided the materials and carried out additional experiments of revision with SH. HT contributed to analysis and interpretation of the data and review of the article. KH and MO supervised and aided in the conduction of the experiments. All authors read and approved the manuscript and agree to be accountable for all aspects of the research in ensuring that the accuracy or integrity of any part of the work are appropriately investigated and resolved.

\section{Ethics approval and consent to participate}

All experimental procedures were approved (no. 3138) by the Osaka City University Ethics Committee, and all patients provided informed consent for collection and analysis of the specimens.

\section{Patient consent for publication}

Not applicable.

\section{Competing interests}

The authors declare that there are no competing interests regarding this study.

\section{References}

1. Ajani JA, Lee J, Sano T, Janjigian YY, Fan D and Song S: Gastric adenocarcinoma. Nat Rev Dis Primers 3: 17036, 2017.

2. Mizrak Kaya D, Harada K, Shimodaira Y, Amlashi FG, Lin Q and Ajani JA: Advanced gastric adenocarcinoma: Optimizing therapy options. Expert Rev Clin Pharmacol 10: 263-271, 2017.

3. Gu L, Chen M, Guo D, Zhu H, Zhang W, Pan J, Zhong X, Li X, Qian $\mathrm{H}$ and Wang X: PD-L1 and gastric cancer prognosis: A systematic review and meta-analysis. PLoS One 12: e0182692, 2017.

4. Galdiero MR, Garlanda C, Jaillon S, Marone G and Mantovani A: Tumor associated macrophages and neutrophils in tumor progression. J Cell Physiol 228: 1404-1412, 2013.

5. Kataoka K, Deleersnijder A and Lordick F: Will molecular target agents enable the multidisciplinary treatment in stage IV gastric cancer? Eur J Surg Oncol 43: 1835-1845, 2017.

6. Hiramatsu S, Tanaka H, Nishimura J, Sakimura C, Tamura T, Toyokawa T, Muguruma K, Yashiro M, Hirakawa K and Ohira M: Neutrophils in primary gastric tumors are correlated with neutrophil infiltration in tumor-draining lymph nodes and the systemic inflammatory response. BMC Immunol 19: 13, 2018.

7. Tokumoto M, Tanaka H, Ohira M, Go Y, Okita Y, Sakurai K, Toyokawa T, Kubo N, Muguruma K, Maeda K, et al: A positive correlation between neutrophils in regional lymph nodes and progression of gastric cancer. Anticancer Res 34: 7129-7136, 2014.

8. Rakic A, Beaudry P and Mahoney DJ: The complex interplay between neutrophils and cancer. Cell Tissue Res 371: 517-529, 2018.

9. Aulakh GK: Neutrophils in the lung: 'The first responders'. Cell Tissue Res 371: 577-588, 2018.

10. Rosales C, Lowell CA, Schnoor M and Uribe-Querol E: Neutrophils: Their role in innate and adaptive immunity 2017. J Immunol Res 2017: 9748345, 2017.

11. Fridlender ZG and Albelda SM: Tumor-associated neutrophils: Friend or foe? Carcinogenesis 33: 949-955, 2012.

12. Hurt B, Schulick R, Edil B, El Kasmi KC and Barnett C Jr: Cancer-promoting mechanisms of tumor-associated neutrophils. Am J Surg 214: 938-944, 2017.

13. Ying HQ, Deng QW, He BS, Pan YQ, Wang F, Sun HL, Chen J, Liu $X$ and Wang SK: The prognostic value of preoperative NLR, d-NLR, PLR and LMR for predicting clinical outcome in surgical colorectal cancer patients. Med Oncol 31: 305, 2014.

14. Miyamoto R, Inagawa S, Sano N, Tadano S, Adachi S and Yamamoto M: The neutrophil-to-lymphocyte ratio (NLR) predicts short-term and long-term outcomes in gastric cancer patients. Eur J Surg Oncol 44: 607-612, 2018.

15. Feng JF, Huang Y and Chen QX: Preoperative platelet lymphocyte ratio (PLR) is superior to neutrophil lymphocyte ratio (NLR) as a predictive factor in patients with esophageal squamous cell carcinoma. World J Surg Oncol 12: 58, 2014.

16. Cortez-Retamozo V, Etzrodt M, Newton A, Rauch PJ, Chudnovskiy A, Berger C, Ryan RJ, Iwamoto Y, Marinelli B, Gorbatov R, et al: Origins of tumor-associated macrophages and neutrophils. Proc Natl Acad Sci USA 109: 24919-2496, 2012.

17. Zhou J, Nefedova Y, Lei A and Gabrilovich D: Neutrophils and PMN-MDSC: Their biological role and interaction with stromal cells. Semin Immunol 35: 19-28, 2018.

18. Pillay J, Tak T, Kamp VM and Koenderman L: Immune suppression by neutrophils and granulocytic myeloid-derived suppressor cells: Similarities and differences. Cell Mol Life Sci 70: 3813-3827, 2013.

19. Nywening TM, Belt BA, Cullinan DR, Panni RZ, Han BJ, Sanford DE, Jacobs RC, Ye J, Patel AA, Gillanders WE, et al: Targeting both tumour-associated CXCR2(+) neutrophils and CCR2(+) macrophages disrupts myeloid recruitment and improves chemotherapeutic responses in pancreatic ductal adenocarcinoma. Gut 67: 1112-1123, 2018.

20. Kato Y, Yashiro M, Noda S, Tendo M, Kashiwagi S, Doi Y, Nishii T, Matsuoka J, Fuyuhiro Y, Shinto O, et al: Establishment and characterization of a new hypoxia-resistant cancer cell line, OCUM-12/Hypo, derived from a scirrhous gastric carcinoma. Br J Cancer 102: 898-907, 2010. 
21. Immune suppression and infections. Keeping a balance. Mayo Clin Health Lett 31: 4-5, 2013.

22. Ostanin DV, Kurmaeva E, Furr K, Bao R, Hoffman J, Berney S and Grisham MB: Acquisition of antigen-presenting functions by neutrophils isolated from mice with chronic colitis J Immunol 188: 1491-1502, 2012.

23. Cassatella MA: Human mature neutrophils as atypical APC Blood 129: 1895-1896, 2017

24. Singhal S, Bhojnagarwala PS, O'Brien S, Moon EK, Garfall AL, Rao AS, Quatromoni JG, Stephen TL, Litzky L, Deshpande C, et al: Origin and role of a subset of tumor-associated neutrophils with antigen-presenting cell features in early-stage human lung cancer. Cancer Cell 30: 120-135, 2016.

25. Wang TT, Zhao YL, Peng LS, Chen N, Chen W, Lv YP, Mao FY, Zhang JY, Cheng P, Teng YS, et al: Tumour-activated neutrophils in gastric cancer foster immune suppression and disease progression through GM-CSF-PD-L1 pathway. Gut 66: 1900-1911, 2017

26. Zhang X and Xu W: Neutrophils diminish T-cell immunity to foster gastric cancer progression: The role of GM-CSF/PD-L1/PD-1 signalling pathway. Gut 66: 1878-1880, 2017

27. Sakimura C, Tanaka H, Okuno T, Hiramatsu S, Muguruma K, Hirakawa $\mathrm{K}$, Wanibuchi $\mathrm{H}$ and Ohira $\mathrm{M}$ : B cells in tertiary lymphoid structures are associated with favorable prognosis in gastric cancer. J Surg Res 215: 74-82, 2017.

28. Tamura T, Ohira M, Tanaka H, Muguruma K, Toyokawa T, Kubo N, Sakurai K, Amano R, Kimura K, Shibutani M, et al: Programmed death-1 ligand-1 (PDL1) expression is associated with the prognosis of patients with stage II/III gastric cancer. Anticancer Res 35: 5369-5376, 2015

29. Abbas M, Steffens S, Bellut M, Becker JU, Großhennig A, Eggers H, Wegener G, Kuczyk MA, Kreipe HH, Grünwald V, et al: Do programmed death 1 (PD-1) and its ligand (PD-L1) play a role in patients with non-clear cell renal cell carcinoma? Med Oncol 33: 59, 2016.
30. Hino R, Kabashima K, Kato Y, Yagi H, Nakamura M, Honjo T, Okazaki T and Tokura Y: Tumor cell expression of programmed cell death-1 ligand 1 is a prognostic factor for malignant melanoma. Cancer 116: 1757-1766, 2010.

31. Bowers NL, Helton ES, Huijbregts RP, Goepfert PA, Heath SL and Hel Z: Immune suppression by neutrophils in HIV-1 infection: Role of PD-L1/PD-1 pathway. PLoS Pathog 10: e1003993, 2014.

32. Cheng Y, Li H, Deng Y, Tai Y, Zeng K, Zhang Y, Liu W, Zhang Q and Yang Y: Cancer-associated fibroblasts induce PDL1 $1^{+}$neutrophils through the IL6-STAT3 pathway that foster immune suppression in hepatocellular carcinoma. Cell Death Dis 9: 422, 2018.

33. Galdiero MR, Varricchi G, Loffredo S, Mantovani A and Marone G: Roles of neutrophils in cancer growth and progression. J Leukoc Biol 103: 457-464, 2018.

34. Huang X, Pan Y, Ma J, Kang Z, Xu X, Zhu Y, Chen J, Zhang W, Chang $\mathrm{W}$ and $\mathrm{Zhu} \mathrm{J}$ : Prognostic significance of the infiltration of $\mathrm{CD}_{163^{+}}$macrophages combined with $\mathrm{CD}^{2} 6 \mathrm{~b}^{+}$neutrophils in gastric cancer. Cancer Med 7: 1731-1741, 2018.

35. Mishalian I, Bayuh R, Zolotarov L, Levy L, Singhal S, Albelda SM and Fridlender ZG: Tumor-associated neutrophils (TAN) develop protumorigenic properties during tumor progression. Cancer Immunol Immunother 62: 1745-1756, 2013.

36. Sagiv JY, Michaeli J, Assi S, Mishalian I, Kisos H, Levy L, Damti P, Lumbroso D, Polyansky L, Sionov RV, et al: Phenotypic diversity and plasticity in circulating neutrophil subpopulations in cancer. Cell Rep 10: 562-573, 2015.

37. Fridlender ZG, Sun J, Kim S, Kapoor V, Cheng G, Ling L, Worthen GS and Albelda SM: Polarization of tumor-associated neutrophil phenotype by TGF-beta: 'N1' versus 'N2' TAN Cancer Cell 16: 183-194, 2009. 